\title{
De raadsman en de TBS
}

\author{
N.A. Heidanus*
}

\section{Tbs-ontduiking}

Laat ik maaar direct controversieel beginnen: de laatste jaren adviseer ik in principe mijn strafcliënten om, indien verdacht van een emstig strafbaar feit, niet mee te werken aan pj-rapportage! De reden hiervan is simpel: het huidige tbs-klimaat is zo somber en ziek, dat een goede advocaat zijn cliënt niet of nauwelijks kan adviseren om mee te werken. Als bedacht wordt dat de afgelopen tien jaar de gemiddelde behandelingsduur ruimschoots is verdubbeld van circa 4,5 jaar naar 9,5 jaar, dan kan een advocaat met goed fatsoen die maatregel niet aanbevelen. Het advies aan een verdachte kan overigens anders zijn als over hem of haar al eerder belastende psychiatrische rapportage is uitgebracht, want dan kan de rechter op basis van die oude rapportages wel tbs met dwangverpleging opleggen. Een weigering is dan soms onverstandig.

Ik vind het oprecht jammer dat ik mij vaak genoodzaakt voel mijn (soms gestoorde) cliënten te adviseren niet mee te werken aan pj-rapportage, omdat de maatregel van tbs soms nuttig en passend kan zijn. Het goede van de tbs wordt mijns inziens onvoldoende uitgedragen. Succes in de tbs blijft onzichtbaar en onbesproken, terwijl er positieve verhalen en goede resultaten verteld kunnen worden. Genoeg cliënten zijn goed terechtgekomen en hebben uiteindelijk nog een positieve bijdrage aan onze samenleving kunnen leveren. Er is verder een grote groep die in ieder geval zonder incidenten en recidive in de samenleving kan functioneren.Maar ik begrijp heel goed dat cliënten de eventuele oneindigheid en grote onzekerheid van de maatregel niet willen en dat ze een tbs willen voorkomen. Zeker als het een relatief licht tbs-indexdelict betreft. ${ }^{1}$ Vooral de gedachte dat een tbs'er tamelijk

* Niek Heidanus is als strafrechtadvocaat werkzaam bij Yspeertvwl Advocaten.

1 Denk bijvoorbeeld aan afpersing, bedreiging of stalking. 
gemakkelijk en snel op een longstay-afdeling terecht kan komen en dus levenslang tegen zijn wil opgesloten kan worden, maakt de maatregel zeer omstreden. Gelet op het huidige tbs-klimaat; dat wordt gekenmerkt door de sterk toegenomen behandelingsduur, de veel beperktere verlofmogelijkheden en de veel grotere kans op plaatsing in de longstay, is het begrijpelijk dat een verdachte liever een langere gevangenisstraf ondergaat dan tbs. De tbs is hier door op slot gedraaid. Een verdachte wil liever 15 jaar kale gevangenisstraf, dan 10 jaar met tbs!

De tbs-behandeling helpt, maar duurt veel te lang. Uit de recidivecijfers volgt dat een behandeling helpt en dat de samenleving daar veiliger van wordt. Circa $70 \%$ van de langgestraften recidiveert, tegenover nog geen $20 \%$ van de tbs'ers. ${ }^{2}$ De tragiek is echter dat de samenleving en de politiek deze belangrijke feiten niet begrijpen of wensen te begrijpen. Bij ieder incident in de tbs moet de Minister van Justitie -met spoed en de staart tussen de benennaar de Tweede Kamer en moeten er steeds opnieuw allerlei ferme en ingrijpende maatregelen tegen tbs'ers worden genomen.

\section{De samenleving bijt zichzelf in de staart}

De samenleving en politiek vragen steeds om meer vergelding en veiligheid, maar ze krijgen het omgekeerde, namelijk meer gestoorde ex-delinquenten die onbehandeld in de maatschappij terugkeren en op termijn weer zullen recidiveren. De samenleving bijt zichzelf dus in de staart. Doordat de tenuitvoerlegging van de maatregel zo onaantrekkelijk is gemaakt, wil iedereen uit de tbs blijven. Dit heeft geleid tot weigerende observandi. Als het systeem goed zou functioneren en de tenuitvoerlegging van de maatregel rechtvaardig en korter zou zijn, dan zouden meer verdachten de tbs als reële optie kunnen beschouwen. Voor advocaten zou het dan gemakkelijker zijn deze - in potentie goede - maatregel te adviseren. Het tegendeel is het geval. De burger is boos, de politiek schreeuwt moord en brand en de media speelt een dubbelhartige rol.

2 L.M. Bergman en B.S.J. Wartna, Recidive TBS 1974-2006, Ontwikkelingen in de strafrechtelijke recidive van ex-terbeschikkinggestelden: een tussenverslag, Den Haag: WODC Factsheet 2010-4, september 2010. In 1999-2003 bedroeg de recidive bij extbs'ers 19,5\% en in 2004-2006 17,7\%, terwijl de 'tbs-waardige' recidive 3,4 \% bedroeg. 
De burger is boos als een verdachte niet meewerkt aan een tbs-onderzoek. Illustratief is de website 'ditkannietlanger.nl' waar gevraagd wordt een handtekening te zetten ten behoeve van een burgerinitiatief. ${ }^{3}$ Via dit burgerinitiatief is het onderwerp van tbs-ontduiking op de agenda van de Tweede Kamer gezet. Een citaat uit een internetberichtje:

\begin{abstract}
'De website is een initiatief van de ouders van een 7-jarig meisje dat een jaar geleden werd ontvoerd naar een camping in Brielle en daar werd misbruikt. De daders kregen allebei een gevangenisstraf, maar één van de daders weigerde mee te werken aan een psychologische test en kreeg daardoor geen tbs. De ouders van het meisje zijn woedend omdat deze dader zo straks zonder behandeling kan terugkeren in de maatschappij. Met deze handtekeningenactie hopen de ouders een wetswijziging te kunnen afdwingen die ertoe zal leiden dat geesteszieke criminelen niet aan behandeling kunnen ontkomen. Er zijn middels de handtekeningen voldoende steunbetuigingen binnengekomen om de kwestie op de agenda van de Tweede Kamer te krijgen. De Tweede Kamer sprak er deze week nog schande van dat verdachten onder een dreigende tbs-behandeling uit proberen te komen door onderzoek te weigeren. Minister Ernst Hirsch Ballin (Justitie) deelt de zorg van de Kamer., ${ }^{4}$
\end{abstract}

De boosheid en frustratie van die ouders is goed te begrijpen. Het is immers ronduit onbevredigend dat een potentieel gestoorde dader niet behandeld kan worden, omdat deze alle medewerking aan een onderzoek heeft geweigerd. Maar echt hypocriet vind ik de leden van de Tweede Kamer en de Minister van Justitie, die naar aanleiding van dit burgerinitiatief moord en brand schreeuwen. Eerst hebben zij het tbs-systeem op slot gedraaid en vervolgens wordt door hen moord en brand geschreeuwd als een verdachte niet in dit zwaar aangetaste systeem wil worden geplaatst. Parlementariërs en de Minister van Justitie komen huichelachtig en ongeloofwaardig over. Kennelijk hebben politici niets geleerd van de krachtige aanbevelingen van de Commissie Visser. ${ }^{5}$ Deze Commissie bracht in 2006 een helder rapport uit over de tbs, met de nog steeds actuele en zelfs een beetje cynische titel: 'Tbs, vandaag over gisteren en morgen'. Aanleiding voor dit rapport was een aantal tbs-incidenten. Eén van de aanbevelingen van de Commissie was dat de politiek terughoudend zou zijn bij incidenten, juist omdat de medialogica

3 www.ditkannietlanger.n1

4 www.blikoponieuws.nl/bericht/111645/Tbs-onduiking_op_agenda_Tweede_Kamer_door _burgerinitiatief.html

5 Kamerstukken II 2005/06, 30250, nrs 4-5. 
ver te zoeken is. De Commissie heeft uitdrukkelijk aangegeven dat de werkelijkheid vertekend overkomt door de manier waarop beelden uit de tbs door de politiek worden neergezet. Doordat de politiek zich heeft bezondigd aan "framing" en niet aflatend opportunisme, is het tbs-systeem meer op slot gekomen en dichtgeslibd. Politici namen zich voor om niet steeds te reageren op elk incident in de tbs. Het was een vals voornemen. Politici winden zich nog steeds publiekelijk op over de tbs als ze ermee kunnen scoren. Om met Obama te spreken: 'Het is voor politici gewoonte geworden om angst voor criminaliteit te gebruiken om stemmen te winnen'. In Nederland is dat helaas niet anders.

De media hebben dezelfde dubbelhartige houding. Na een tbs-incident is de pers meer geïnteresseerd in de vraag wie er wordt ontslagen en welke nieuwe harde maatregelen er zullen worden genomen, dan in de vraag wat er eigenlijk gebeurd is en hoe het systeem werkt.

Tijdens een symposium over de toekomst van de tbs heb ik als één van de sprekers bedroefd vastgesteld dat de politiek en media een tendentieus en irreëel beeld schetsen van het tbs-systeem. Incidenten worden uitvergroot en als schokkend nieuws gepresenteerd met schreeuwerige koppen. Illustratief is een reeks artikelen in De Telegraaf over een ex-marinier die familieleden had gedood en door de Fokkenswet na één derde van zijn gevangenisstraf in de tbs was terechtgekomen. Het gevolg van deze publicatie was dat de toenmalige staatssecretaris van Justitie, Albayrak, besloot om de Fokkensregeling per direct te bevriezen en serieus overwoog om de regeling af te schaffen. ${ }^{6}$ Een regeling die nog geen twintig jaar geleden is ingevoerd met als doel dat een zieke geest (een patiënt) sneller aan zijn behandeling kan beginnen, zodat de effectiviteit van de behandeling wordt vergroot en op termijn de samenleving veiliger zal worden. Dit is een schoolvoorbeeld van ondoordachte en misplaatste politiek, want langer straffen en later starten met de tbs- behandeling zal met zekerheid niet bijdragen aan een effectiever en efficiënter tbs-systeem. Vanuit het perspectief van het rapport van de Commissie Visser moet worden gezegd dat de politiek steeds meer het tbssysteem afbreekt en steeds minder met vandaag en morgen bezig is.

6 Kamerstukken II 2009/10, 29452, nr. 123. Voormalig Staatsecretaris van Justitie, Albayrak, maakte deel uit van de Commissie Visser. 


\section{De tbs kampt met een groot imagoprobleem}

De effectiviteit van de tbs blijkt scherp uit de genoemde recidivecijfers. ${ }^{7}$ Toch gaapt er een grote kloof tussen het maatschappelijke beeld en de feitelijke realiteit van de tbs. Er wordt steeds meer aan de wortels van het tbssysteem gezaagd, terwij1 dit systeem juist gekoesterd zou moeten worden. De media, de politiek en de burgers moeten ervan doordrongen raken dat dankzij de tbs grote rampen worden voorkomen en ernstige geweldsdelinquenten langer uit de samenleving worden verwijderd. Zonder de tbs zouden er jaarlijks tientallen potentiële moordenaars en verkrachters meer op straat rondlopen dan nu het geval is.

De politiek en de media zijn onmisbaar bij het creëren van een breder maatschappelijk draagvlak voor de tbs. Als verlof en resocialisatie van de tbs'er maatschappelijk gezien niet wordt aanvaard, dan dreigt een belangrijke verworvenheid van onze strafrechtelijke beschavingsgeschiedenis, namelijk de tbs, verloren te gaan. Het politieke debat over de tbs is al jaren in handen van de tegenstanders. Waar zijn de politici die werkelijk bereid zijn hun nek uit te steken voor de toekomst van het tbs-systeem? Waar zijn de politici die zich niet bezondigen aan politiek opportunisme en die wel verder nadenken dan de tekst van hun oneliner? Waarom zijn de uitstroomcijfers zoveel slechter geworden en is de behandelingsduur zo sterk toegenomen? Omdat het goede van de tbs onvoldoende wordt uitgedragen. In het buitenland is men nota bene jaloers op ons systeem. Zoals gezegd, de tbs kampt met een groot imagoprobleem.

\section{Oprichting Forum Tbs}

Ik ben dat negativisme beu en vind dat iedereen wakker geschud moet worden. Uit bezorgdheid over alle negatieve ontwikkelingen en de toekomst van de tbs hebben een aantal mensen uit het tbs-veld een 'Forum Tbs' opgericht. ${ }^{8}$ Het Forum Tbs stelt zich ten doel om een krachtig tegengeluid te laten horen in het politieke en publieke debat over de tbs. Het Forum Tbs komt op voor

7 L.M. Bergman en B.S.J. Wartna, Recidive TBS 1974-2006, Ontwikkelingen in de strafrechtelijke recidive van ex-terbeschikkinggestelden: een tussenverslag, Den Haag: WODC Factsheet 2010-4, september 2010

8 Denk aan rechters, leden van het Openbaar Ministerie, directeuren van klinieken en gedragsdeskundigen. 
de ideële uitgangspunten van de tbs en zal met alle publicitaire middelen proberen uit te dragen dat juist dankzij de tbs ernstige delicten worden voorkomen en de samenleving veiliger wordt. Binnenkort zullen de initiatiefnemers met het Forum Tbs naar buiten treden. Het is cruciaal dat een reëler beeld van de tbs ontstaat en dat het beleid van de overheid minder eenzijdig wordt bepaald door incidenten.

Hoe kan de beeldvorming van de tbs-sector worden verbeterd? Feit is dat burgers nauwelijks een goed beeld hebben van de tbs-maatregel, de uitvoering, de sector en de patiënt.

De kennis die men heeft is fragmentarisch en inadequaat. Primair overheerst bij burgers de emotie. De emotie van angst en afkeer van de tbs, waarbij wordt gedacht dat tbs'ers 'Hannibals' zijn. Dat levensgevaarlijke tbs'ers met bosjes tegelijk de kliniek uitmarcheren en dat deze psychopaten geen mogelijkheid onbenut laten om opnieuw te moorden en te verkrachten.

Enkele jaren geleden heb ik mijn voetbalteam (Be Quick 1887) meegenomen voor een voetbalwedstrijd in de Van Mesdagkliniek. Mijn teamgenoten, normaal ontwikkelde burgers, waren totaal verrast door de sportiviteit en hartelijkheid van de tbs'ers. Ze verwachtten kennelijk 'Hannibals' te treffen, terwijl de jongens correct, hartelijk en heel sportief waren.

Deze ontmoeting was een goede eye-opener voor hen. De werkelijkheid bleek zoveel anders dan het beeld dat door de media en politiek was gecreeerd.

Recentelijk berichtte misdaadverslaggever Peter R. de Vries, groots en met een narcistisch toontje, dat een tbs'er, Koos H., over porno mocht beschikken. Hij meldde verder dat hierover Kamervragen zouden worden gesteld. De wijze waarop het nieuws werd gebracht was schokkender dan het nieuws zelf. De tragiek is dat de psychopathische Koos H. helemaal geen tbs'er is, maar een levenslang gestrafte zonder enig perspectief op vrijheid en dat een infiltrant met verborgen camera gebruikt is om oud nieuws op te nemen.

De feitelijke kennis over tbs is veelal zeer pover. De media schetsen simplistische beelden die ver van de werkelijkheid staan, maar die tegelijkertijd heel moeilijk slijten. De enige manier om door deze emotie heen te breken is het hanteren van een eerlijke en zakelijke benadering. Bovendien moet er een forum worden gevonden om het vertekende beeld van de tbs aan de kaak te 
stellen. Steeds moet hardop de vraag worden gesteld wat het alternatief is voor de tbs.

Steeds moeten de recidivecijfers worden herhaald en moet de effectiviteit van het tbs-systeem worden onderbouwd. Niet onvermeld mag blijven dat de tbs kan uitmonden in plaatsing op een longstay-afdeling als een patiënt onbehandelbaar en ongeneeslijk ziek is. Dit betekent dat ook moet worden uitgelegd dat verlof en vrijheid zeker geen vanzelfsprekendheid is.

De tbs-sector moet zich realiseren dat het noodzakelijk is om volledig en transparant verantwoording af te leggen over incidenten. In mijn eigen omgeving (familiefeestjes, rotary's en voetbalvrienden) probeer ik een ander perspectief te laten zien en de menselijke kant te benadrukken. Tijdens diverse lezingen geef ik legio voorbeelden van cliënten die het zeker niet getroffen hebben in het leven en meer als patiënt en als stumper moeten worden beschouwd dan als een crimineel. En dat werkt. De schellen vallen vaak van de ogen en met concrete praktijkvoorbeelden wordt een ander perspectief getoond.

De tbs-sector en het Forum Tbs moeten benadrukken dat de tbs-maatregel een containerbegrip is. Er zijn grote verschillen in bijvoorbeeld de aard van de ziekte van de tbs'er, de ernst van het gepleegde delict en wat betreft de tenuitvoerlegging, de fase van de behandeling. Er moet echter niet alleen iets aan de negatieve beeldvorming over de tbs'er en de destructieve incidentenpolitiek worden gedaan. Ook het tbs-stelsel zelf moet stevig veranderd worden.

\section{Het vijfpunten-plan}

Hoe kan het tbs-systeem worden verbeterd? Mijn voorstel zou zijn om een vijfpunten-plan in te voeren. Allereerst moet de behandelingsduur substantieel worden verkort. Er moeten meer (passende) uitstroommogelijkheden worden gerealiseerd, onder andere met het 'stepped-care-principe' via BOPZ, GGZ, RIBW of FPT/reclassering. Het is bijvoorbeeld al jaren bekend dat teveel chronisch psychiatrische patiënten, zoals schizofrenie patiënten, onnodig lang in de tbs verblijven. Menselijke ellende hoort thuis in de GGZ, niet in de tbs.

In de tweede plaats moet de kwaliteit van de behandeling en het behandelaanbod verbeteren. Al jaren pleit ik voor een gespecialiseerde opleiding voor 
personeel van tbs-klinieken. Verder moet geïnvesteerd worden in meer effectieve therapie en minder wachtlijsten. Nu gaat veel kostbare tijd verloren met wachten, weinig doelmatige creatieve- en arbeidstherapie en allerlei groepsactiviteiten.

In de derde plaats bepleit ik een soepeler verlofbeleid. Het duurt veel te lang alvorens verlof wordt aangevraagd. Als dan eindelijk na jaren wachten verlof wordt aangevraagd, is het een bureaucratische muur die moet worden beslecht. Bovendien zijn de fasen van het verlof buitensporig lang geworden. De algemene regel dat een cliënt eerst een jaar lang (gefaseerd) beveiligd en begeleid verlof moet praktiseren, voordat onbegeleid verlof kan worden aangevraagd, is onzinnig. Verder is het onnodig om zo snel het verlof in te trekken. ${ }^{9}$ Een versoepeling van het verlofbeleid zou kunnen inhouden dat er een helder systeem van verlof wordt ingevoerd. Een tbs'er heeft recht op verlof, tenzij er gerechtvaardigde bijzondere omstandigheden zijn die maken dat het verlof niet kan worden verleend. Concreet kan gedacht worden aan het volgende systeem: na een jaar recht op begeleid verlof; na twee jaar recht op onbegeleid verlof en na maximaal vier jaar recht op transmuraal verlof, tenzij er gerechtvaardigde bijzondere omstandigheden zijn.

In de vierde plaats zou de tbs gemaximeerd of genormeerd moeten worden. Er zou gedifferentieerd moeten worden naar de aard van het delict en de ernst van de ziekte. $\mathrm{Nu}$ kan een tbs'er voor een relatief licht delict heel lang en zelfs levenslang worden opgesloten. Vastgelegd moet worden dat voor lichtere delicten de tbs wordt gemaximeerd tot 4, 6 of 8 jaren. Het systeem kan het niet verdragen dat iemand voor bijvoorbeeld bedreiging 16 jaar wordt opgesloten. Normering kan onder meer worden bereikt door invoering van een verlofstelsel zoals onder het derde punt is aangegeven. Verder moet er een plan van aanpak komen en moeten zowel de patiënt als de kliniek een behandelovereenkomst sluiten die juridisch afdwingbaar is.

Als vijfde en laatste punt moet de rechter zich actiever met de tenuitvoerlegging van de tbs bemoeien. Nu kan de verlengingsrechter hooguit een aanwijzing of advies aan de kliniek geven. De rechter zou zich actiever moeten kunnen bemoeien met het traject en de wijze van tenuitvoerlegging van de

9 Nu geldt dat als de tbs'er om welke reden dan ook niet tijdig terug keert of wordt overgeplaatst zijn verlof wordt ingetrokken. Verder wordt het verlof direct ingetrokken bij een externe overplaatsing naar een andere kliniek en bij iedere aangifte, hoe zwak deze ook is. 
tbs. Zo zou de rechter de bevoegdheid moeten krijgen om een trajectbeslissing te nemen, dat wil zeggen dat hij bijvoorbeeld de tbs ambtshalve kan omzetten in een rechterlijke machtiging of een tbs'er kan terugplaatsen van de longstay-afdeling naar een behandelafdeling. Dat zou een grote vooruitgang betekenen.

Als strafrechtadvocaat sta ik midden in het tbs-moeras en ken het systeem als ervaringsdeskundige heel goed. Met het vijfpuntenplan heb ik een concrete aanzet voor het behoud en betere tenuitvoerlegging van de tbs willen geven. $^{10}$

10 In september 2010 hebben het ODO (Onderling directeuren overleg van Forensisch Psychiatrische Centra) en LBHIV (Landelijk Beraad Hoogst Inhoudelijk Verantwoordelijken) een visienota uitgebracht met de titel: 'Forensische zorg in perspectief'. Hierin zijn goede voorstellen gedaan. $\mathrm{Zo}$ is in belangrijke mate het derde punt van mijn voorstel in de visienota opgenomen. 